\title{
Epistemología, método y cientificidad del Derecho
}

\author{
Isaac Enrique Castro Cuba Barineza, $\mathrm{PhD} *$
}

* Ingeniero metalúrgico y Abogado (Universidad Nacional San Agustín de Arequipa), Licenciado en Educación (Facultad de Teología Pontificia y Civil de Lima), Maestro en docencia universitaria y Doctor en Educación (Universidad Particular San Martin de Porres, Lima), PhD. en Filosofía (Graduate Theological Foundation, Indiana-USA). Actualmente es profesor de posgrado en la Universidad Andina de Cusco, Universidad Nacional San Antonio Abad de Cusco y profesor asociado de la Academia de la Magistratura.

\section{INTRODUCCIÓN}

Resulta alentador en el entorno académico de las universidades peruanas, el hecho de que hace más de una década se haya tornado recurrente la mención a la investigación científica, al ser considerada como tema relevante - $\mathrm{y}$ hasta transversal—, en la formación de los futuros profesionales. Sin embargo, la realidad nos muestra que es poco lo que se ha podido avanzar en la producción de conocimientos científicos derivados, precisamente, de la actividad académica universitaria. Puede parecer mezquina mi afirmación, pero una simple comparación con la producción de conocimientos entre nuestras mejores universidades peruanas y cualquier universidad que figura dentro del ranking de las cien mejores universidades del mundo —elaborado por la Academic Ranking of World Universities ${ }^{6}$-, sin duda ratifica con creces mi afirmación. Claro está, que reconozco las diferencias contextuales entre unas y otras, y no resto mérito de manera alguna, al camino esperanzador iniciado para dar impulso a la investigación en nuestras universidades.

La investigación científica, aparte de ser metódica, debe dejarse guiar por los ojos de la epistemología, caso contrario, carece de una orientación racional y de una fundamentación consistente, respecto a la naturaleza y validez de los conocimientos a los que llega. De allí la necesidad de que, quienes se ocupan de guiar el afán investigador de los estudiantes en la universidad, deban estar sólidamente asentados en fundamentos epistemológicos que les permitan tener una noción clara de lo que se entiende por ciencia y de los caminos adecuados

\footnotetext{
${ }^{6}$ Para el ranking global, como señala la ARWU, «toma en consideración aquellas universidades con poseedores (profesores o alumnos) de premios nobel o medallas Fields, investigadores altamente citados y artículos publicados en Nature o Science durante los últimos diez años. Además, también se incluyen las universidades con una cantidad significativa de artículos indexados por Science Citation Index - Expanded (SCIE) y Social Science Citation Index (SSCI).»
} 
que deben elegirse, para alcanzar conocimientos de carácter científico respecto a la realidad. En la primera parte del desarrollo del presente ensayo, hago un esbozo de las distintas perspectivas epistemológicas que han contribuido a perfilar el carácter actual de la ciencia, por supuesto, un carácter inacabado y en construcción permanente en la historia.

En el caso específico del "Derecho" sigue en cuestión, en círculos cada vez más reducidos, el carácter de su cientificidad. Querer someter a examen crítico su estatus científico desde la perspectiva del positivismo inductivista, es un despropósito reduccionista y anacrónico que, naturalmente, descalificará su cientificidad. Entender y aceptar su ser ontológico como realidad cultural que puede ser reducida cognitivamente al análisis e interpretación por la racionalidad humana y, por supuesto, también asumir una concepción de ciencia más abierta a las posibilidades del conocimiento de la realidad fenoménica nos conduce, sin objeciones insalvables, a una aceptación de su cientificidad.

La ciencia del derecho, como otras ciencias, se muestra dúctil a las transformaciones sociales en la historia y, debe buscar, de manera dinámica, que sus contenidos se correspondan a los nuevos paradigmas. La investigación jurídica debe ser capaz de ir más allá de los presupuestos establecidos por la 'ciencia normal' (según lo discurrido por Kuhn) o el statu quo jurídico imperante, y lo debe hacer reconociendo la naturaleza de su objeto de estudio: que es la que determina el abordaje metodológico que se dé a la investigación. En torno a estos aspectos discurriremos en el desarrollo del presente ensayo.

\section{DESARROLLO}

Uno de los aspectos referidos al "Derecho", y que aún no ha sido agotado en la discusión epistemológica, es el que se refiere a su cientificidad. El tema se enmarca dentro del contexto de la demarcación entre lo que debe entenderse como ciencia y seudociencia. Antes de abordar directamente una posición frente al problema, debemos esbozar algunas ideas en torno a la epistemología de la ciencia moderna y contemporánea. En principio, es conveniente recordar que el sustento teórico-filosófico que asiste a la ciencia moderna es el positivismo filosófico, aunque hunde también sus raíces en el empirismo. El término «positivismo» fue utilizado por vez primera por el filósofo y sociólogo francés Augusto Comte (1798-1857). 
Para el positivismo, el único conocimiento autentico es el científico y dicho conocimiento surge, solo y únicamente, de la comprobación de las hipótesis mediante el método científico.

Al respecto debemos recordar que esta visión de la ciencia — que se manifiesta en el paradigma cuantitativo, racionalista y empírico-analítico-, es la que ha venido dominando en la comunidad científica, instituyéndose como consecuencia, un monismo metodológico que excluye todo otro camino de aproximación al conocimiento de la realidad de manera científica. Otra de las características que particularizan al positivismo científico es, su visión fragmentada de la realidad, existe una realidad independiente del ser humano que la conoce, y este tiene acceso a dicha realidad mediante los sentidos, la razón y los instrumentos adecuados. Así, lo que perciben los sentidos es considerado como real —y la verdad no sería otra cosa que la correspondencia entre lo que se conoce y la realidad que se descubre-.

Respecto a ello en 1934, Karl Popper publica su Logik der Forschung (traducido al español como 'Lógica de la investigación científica'), en dicha obra se manifiesta crítico, contra el positivismo y desarrolla su teoría de la «falsación», estableciendo así el llamado racionalismo crítico. El afán de Popper, en su análisis lógico del positivismo, es absolver preguntas como: ¿Cómo podemos determinar si una teoría es correcta?, ¿cómo diferenciar las teorías científicas y las teorías no científicas? y ¿qué es lo que da validez a las teorías científicas? En sus obras, Popper manifiesta —explícitamente— su afán por rechazar radicalmente la inducción como criterio de verificación del conocimiento científico: «En cuanto a la inducción (o lógica inductiva, comportamiento inductivo, aprendizaje por inducción o repetición o, por 'instrucción')» — dice Popper en su autobiografía $(1974,29)$ — «afirmo que no hay tal cosa». Así, para Popper, el criterio de demarcación entre la ciencia y la seudociencia no es empírico sino lógico, puesto que las teorías no son derrotadas por un único y decisivo experimento, sino que las teorías compiten unas con otras y prevalece la más consistente y convincente, hasta que no aparezca otra que la supere. En su crítica a la verificación empírica de los conocimientos científicos, Popper muestra que la inducción no puede darnos conocimientos absolutos, pues siempre cabe una probabilidad en contrario, de lo que se concluye: que los conocimientos científicos no son verdades absolutas sino que se constituyen solo en probabilísticas. 
Así pues, el proceso de la ciencia, según Popper, debe seguir el método de eliminación por ensayo y error (en el lenguaje de la lógica formal el modus tollens), señala que:

Todas las discusiones científicas comienzan con un problema ( $\mathrm{Pj})$, para el cual ofrecemos una especie de solución tentativa —una teoría tentativa (TI) —; esta teoría luego es criticada, en un esfuerzo por eliminar el error (EE) y, como en el caso de la dialéctica, este proceso se renueva a sí mismo: la teoría y su revisión crítica dan lugar a nuevos problemas (P2). (Autobiografía, 1974a, 105106).

De lo dicho se entiende, que una teoría es científica si es 'falsable', es decir, si es empíricamente refutable. Al respecto, Popper afirma en su "Lógica de la investigación científica": «la racionalidad científica no consiste en buscar la comprobación de que se está en lo cierto, sino en permitir la posibilidad de que se pruebe que se está equivocado.»

Por otra parte, en tiempos contemporáneos a Popper, destaca también la fundación y el desarrollo del pensamiento epistemológico del Wiener Kreis (Círculo de Viena) en 1922, por Johan Craidoff y Moritz Schlick. Este grupo que, además, tenía entre sus miembros destacados a Rudolf Carnap, Otto Neurath, Friedrich Waismann, Philipp Frank, Hans Hahn, Herbert Feigl, Víctor Kraft, Félix Kaufmann y Kurt Godel, son llamados neopositivistas. Es destacable el hecho de que son científicos quienes hacen de la epistemología un campo reservado - tradicionalmente - a los filósofos. Su postura epistemológica considera fundamentalmente, que el único tipo de conocimiento no analítico válido es el conocimiento científico, su diferencia con el positivismo del siglo XIX está en el énfasis que le dan al uso de la lógica simbólica como instrumento para diferenciar entre distintos tipos de lenguaje y sus relaciones en el aspecto formal (sintaxis-lógica), como en su contenido (semántica). Otra de sus convicciones esenciales es la afirmación de que el método científico es el único camino para conocer la realidad fenoménica, puesto que la realidad esencial no es de interés para la ciencia, pero es imprescindible tener en cuenta los enunciados del lenguaje científico los que deben expresar perfectamente la realidad, y la forma de saber cómo la construyen, es la verificación directa de cada uno de los enunciados, pero, esta verificación directa solo es posible, si los enunciados miden los fenómenos, lo que realmente se da. Así pues, según los neopositivistas, el error de la metafísica consiste en la concepción de que el pensar puede llevarnos a conocimientos por sí mismo, sin utilización de algún material de la experiencia, 
Luego, a comienzos de los años 60 del siglo XX, se introducen nuevos aportes en la comprensión de la ciencia. En 1962 Thomas Kuhn, historiador y filósofo de la ciencia publica su obra «La estructura de las revoluciones científicas», donde incluye en la reflexión epistemológica la categoría de historia. Para Kuhn, en lo que se refiere a las teorías científicas, no importa su validez científica actual, sino su validez científica en su época; en su momento histórico. En la gestación del conocimiento científico, la historia evidencia una revolución en el proceso científico, revolución vinculada a las cuestiones sociológicas inherentes al quehacer científico. La revolución científica supone dejar de lado una determinada estructura teórica y su posterior substitución por otra que resulta incompatible con la anterior, y como consecuencia de dicha afirmación plantea, que el progreso del saber científico no es acumulativo, dada la inconmensurabilidad de las teorías científicas. Kuhn, coincide con Imre Lakatos (1922 - 1974) en el hecho de que sus concepciones filosóficas deben resistir a las críticas basadas en la historia de la ciencia. El pensamiento de Kuhn, aportó nuevos elementos al debate filosófico en torno a la ciencia, el modelo formalista que imperaba fue enfrentado por su modelo historicista. Kuhn sostuvo que la revolución científica se despliega en la historia en cinco fases: establecimiento de un paradigma imperante en una época histórica, ciencia normal, crisis, revolución científica y, finalmente, el establecimiento de un nuevo paradigma.

Así mismo, en el recorrido analítico del presente ensayo considero, muy relevantes los aportes del filósofo vienés Paul Feyerabend (1924 - 1994), quien en su obra «Tratado contra el método» en 1975, se opone de manera radical a la existencia de estándares invariables de racionalidad, incluido en el ámbito de la ciencia, señala que en la investigación científica lo que determina el método correcto y apropiado es el objeto de la ciencia y no a la inversa, con lo que contradice a lo establecido por el monismo metodológico dominante en esa época. Feyerabend descarta la idea de un método fijo o de una teoría fija de la racionalidad, por el contrario, sostiene el principio del todo sirve en la investigación científica. En su obra citada líneas arriba afirma:

Mi intención no es reemplazar un juego de reglas generales por otro; más bien, mi intención es convencer al lector de que todas las metodologías, incluyendo a las más obvias, tienen sus límites. La mejor manera de mostrar esto es demostrar no solo los límites, sino hasta la irracionalidad de 
algunas reglas que él o ella (los empiristas) posiblemente consideran como básicas. (Feyerabend, P. 1986).

Así también, la postura de Feyerabend (1986) en contra del monismo metodológico es categórica, al afirmar que:

La idea de un método que contenga principios firmes, inalterables y absolutamente obligatorios que rijan el quehacer científico tropieza con dificultades considerables, al ser confrontada con los resultados de la investigación histórica. Descubrimos entonces, que no hay una sola regla, por plausible que sea y, por firmemente basada, que esté en la epistemología, que no sea infringida en una ocasión u otra. (Óp., Cit. 1986).

Es más, considera que una pluralidad metodológica permitirá a los investigadores un acercamiento más fructífero al conocimiento de la realidad. En su tratado contra el método afirma:

Un científico que desee maximizar el contenido empírico de los puntos de vista que sustenta y que quiera comprenderlos tan claramente como sea posible, tiene que introducir, según lo dicho, otros puntos de vista, es decir, tiene que adoptar una metodología pluralista. Debe comparar sus ideas con otras ideas más bien que con la experiencia, y debe intentar mejorar, en lugar de excluir, los puntos de vista que hayan sucumbido en esta competición. (Óp., Cit. 1986).

Por otra parte, durante las tres últimas décadas del siglo XX, se afirman en el escenario de la investigación — particularmente de la realidad social y cultural—, los llamados enfoques cualitativos. Debemos señalar al respecto que no es un enfoque nuevo en la investigación, puesto que podemos encontrar desarrollados trabajos cualitativos en la antigüedad griega (en obras de Herodoto y Aristóteles), y en la etnografía temprana del siglo XV, cuando los pensadores occidentales muestran interés por conocer los orígenes de la cultura y la civilización. Sin embargo, con el auge de la ciencia moderna de corte inductivo y la justificación teórica del positivismo que enfatizan en los objetivos medibles y cuantificables, las investigaciones cualitativas, durante buena parte del siglo pasado, son relegadas al limbo de la seudociencia.

En tal sentido, los principios teóricos en los que se basa el enfoque cualitativo son básicamente: la fenomenología, hermenéutica, etnografía y el constructivismo; aunque es preciso mencionar a importantes antecedentes teóricos de este enfoque como son: la corriente 
funcional estructural, la antropología social británica, la corriente de cultura y personalización de la antropología social americana, la corriente de lingüística antropológica, y la corriente de interacción simbólica. La investigación, según el enfoque cualitativo, epistemológicamente se preocupa por la construcción de conocimiento respecto a la realidad social y cultural desde el punto de vista de quienes la producen y la viven. La aplicación de este enfoque requiere diseños metodológicos diferentes a los que sigue el enfoque cuantitativo, así mismo, en el desarrollo de los estudios cualitativos asumen distinta función las hipótesis y, por supuesto, no es necesario cuantificar variables y someterlas a instrumentos y pruebas estadísticas.

Entre las diversas justificaciones del conocimiento derivado de los estudios cualitativos se halla el constructivismo. Según la teoría constructivista, es el individuo el que construye significados a medida que va aprendiendo la realidad. Dicho aprendizaje se centra en el mismo sujeto, que a partir de experiencias previas formula nuevas construcciones mentales, las que expresan conocimiento de la realidad, cuando el individuo interactúa con el objeto (Piaget), si lo realiza con otros (Vigotsky) o, si es significativo para el sujeto (Ausubel).

Por consiguiente, uno de los propósitos fundamentales de la investigación cualitativa es entender el comportamiento humano y las razones que lo gobiernan. Allí radica su diferencia con la investigación cuantitativa; la investigación cualitativa investiga para conocer y entender las razones de los diferentes aspectos de tal comportamiento, para tal fin, se plantea indagar el por qué y el cómo se tomó una decisión; en cambio, la investigación cuantitativa pretende absolver preguntas tales como: ¿cuál?, ¿dónde?, ¿cuándo?, ¿en qué medida?

Así pues, en este punto de la historia de la ciencia, cuando transitamos casi dos décadas del siglo XXI y hay una aceptación mayor de un pluralismo metodológico en la investigación científica, son oportunas y vigentes las afirmaciones que hacen Strauss, A. y J. Corbin (1998):

La actual es una época de coexistencia, de acercamientos y aceptaciones, aunque no siempre pacífica y convergente. Sin embargo, no sería del todo inexacto decir que es la época de la investigación diferente, en la que la cualitativa ocupa un lugar muy especial. La propuesta de investigación cualitativa se fue concibiendo en el marco del concepto de paradigma ha sido denominada en los últimos años de diversos modos; es una gama de denominaciones que quieren expresar su elemento esencial. (Strauss, A. y J. Corbin 1998): 
De lo dicho hasta este punto podemos concluir que el concepto de ciencia no es rígido, absoluto e inflexible, es un concepto situacional. Los aportes de los epistemólogos mencionados (Popper, Khun, Lakatos, Feyerabend, entre otros) y las teorías que sostienen el enfoque cualitativo, nos distancia más de la visión rígida del 'inductivismo', respecto a la ciencia, y que sostenía desde una perspectiva reduccionista, que el avance de la ciencia solo se puede explicar de manera coherente desde los argumentos razonados de los investigadores, que se fundan en evidencias empíricas e inferencias inductivas. Hoy, la ciencia tiene un nuevo perfil, y es claro que un nuevo paradigma se decanta para ofrecer explicaciones científicas más convincentes frente a cuestionamientos que la visión tradicional de la ciencia no satisface, en particular, en lo que se refiere al fenómeno humano. Al respecto, coincidimos con la afirmación de Vásquez Roca (2006), quien señala que «lo científico es aquello que pueda someterse a una prueba crucial donde se ponga en riesgo su veracidad, o, lo que es lo mismo, que pueda ser falseada». Esto constituye un principio de demarcación entre lo que es y lo que no es científico. Pero, añadimos algo más, que es crucial en el entendimiento de lo que es o no conocimiento científico: me refiero al propósito esencial de la ciencia moderna que no es otro que el conocimiento de la realidad fenoménica, aunque la totalidad de lo real se halle siempre como asignatura pendiente para el conocimiento humano.

Por otro lado, entrando en el tema del derecho y de su cientificidad, nos referirnos primero: al pensamiento de Hans Kelsen respecto al 'carácter de ciencia que le asigna al derecho'. Para Kelsen, el derecho es ciencia jurídica y no 'política del derecho'. Para justificar su cientificidad Kelsen sostiene, que es menester delimitar el objeto de conocimiento de la teoría jurídica. En su obra Reine Rechtslehre, el autor manifiesta su propósito inicial respecto al derecho: «Desde el comienzo mismo, fue mi objetivo elevar la ciencia del derecho, que se agotaba casi completamente - abierta o disimuladamente — en una argumentación jurídicopolítica, al nivel de una auténtica ciencia, de una ciencia del espíritu». Por otra parte, en su libro «El método y los conceptos fundamentales de la teoría pura del derecho», precisa que el derecho "como ciencia, no se siente obligada más que a conocer el 'derecho positivo' en su esencia, y a comprenderlo mediante un análisis de su estructura", por tanto, para Kelsen el objeto de la ciencia jurídica es la norma positiva, todo otro contenido es metajurídico; de allí que concibe al 'derecho' como una ciencia normativa, que se diferencia de las ciencias sobre los hechos o ciencias empíricas. Esta idea de Kelsen de que el derecho se constituye 
como una norma o un sistema de normas da lugar a la edificación de una comprensión teórica, que tiene como centro a la norma jurídica, afirmando una separación radical entre el mundo del "ser" y el "deber ser". Con ello, la ciencia jurídica, en la perspectiva kelseniana, se reduce a un esquema lógico que se enuncia en un juicio hipotético y, cuya única función, es describir la norma jurídica que, como juicio, puede ser verdadero o falso. Por tanto, para Kelsen, la ciencia del derecho tiene como tarea única definir qué es el derecho y cómo analizar su estructura.

Por consiguiente, el análisis de Kelsen respecto a la ciencia del derecho, reduce a esta a un simple esquema lógico, dicho esquema se plantea a través de un juicio hipotético que tiene como tarea única describir la norma jurídica, y siendo así, como juicio puede ser verdadero o falso. Kelsen distingue la ciencia del derecho - que no viene a ser sino un conjunto de proposiciones jurídicas del derecho- que está constituido por normas jurídicas que prescriben la conducta de los seres humanos. La idea inicial de Kelsen de que la norma jurídica general era solo un juicio hipotético o lógico, cambió en la madurez de su pensamiento, de tal manera que, finalmente, concibió a la norma jurídica bajo la forma de un imperativo dictado por la autoridad. Tenemos que destacar el afán de Kelsen de hacer de la ciencia del derecho eso precisamente: una ciencia, claro está, desde unos presupuestos que hoy encuentran objeciones serias que evidencian sus inconsistencias.

Así, la visión que tiene el positivismo jurídico de la ciencia del derecho (inspirado en el pensamiento de Hans Kelsen, Alf Ross, Norberto Bobbio y Herbert Hart, entre otros) parte de una teoría del conocimiento en la que se separa el sujeto del objeto cognoscible. En el caso del derecho, la ley es el objeto cognoscible, lo único objetivo es la norma y nada más, así, ella es la realidad cognoscible de la ciencia del derecho. Por tanto, toda cuestión que deba solucionar la ciencia del derecho se subsume en la ley, y la subsunción es una inferencia lógica que tiene como premisa mayor a la ley, y la premisa menor es lo que se prueba, de acuerdo a los supuestos de la ley, dando como resultado conclusivo: la aplicación de la solución dispuesta por el legislador a los casos planteados por las partes. Así pues, como señala Mercado Pérez (2015), para el positivismo jurídico, « [...] la "cientificidad” del derecho solo sería el proceso usado por el juez para hacer la subsunción». 
Otro denominador común en el pensamiento positivista del derecho, es el afán radical de separar el derecho de la moral, ello con vistas a poder alcanzar el estatus de la cientificidad. Sin embargo, el dualismo de esta teoría no consideró que ella misma depende de elementos no racionales, puesto que los actos de voluntad se sustentan, no se demuestran en cuanto tales. Además, está el hecho innegable de que la praxis judicial se basa de manera indisoluble en juicios de valor, puesto que, cuando el juez debe aplicar la ley, no decide sobre el sentido correcto de esta, sino que "elige" entre diversas interpretaciones posibles, para aplicar la que, a su juicio, constituye ajustada a derecho.

Respecto a lo dicho hay algo que debemos tener en consideración al dilucidar la cientificidad del derecho, y es que él es una manifestación cultural y real del fenómeno humano. El derecho se relaciona, indesligablemente, con la libertad y la razón del hombre, sin que ello signifique llevarlo a los extremos que Kelsen llega, es decir, hasta hacer del orden normativo percibido por la razón, el único objeto de la ciencia jurídica. El ser mismo del derecho está vinculado al fenómeno humano, en ello coinciden las distintas concepciones que del derecho se han generado. Así, el maestro García Maynez (1969) afirma:

En realidad, todos los autores admiten que el derecho es una regulación del proceder de los hombres en vida social, y solo discrepan en lo que atañe a la naturaleza de los preceptos jurídicos. Las divergencias fundamentales giran en torno al problema que consiste en saber si tales preceptos son normas auténticas o exigencias dotadas de una pretensión de validez absoluta, pero desprovistas, en ocasiones, de valor intrínseco. (García Maynez 1969).

Así mismo, una de las objeciones planteadas a la cientificidad del derecho es el carácter cambiante de la norma jurídica. Al respecto, a la luz de la ciencia contemporánea, de la incertidumbre de Heisenberg y, de la relatividad 'einsteniana'; tampoco se puede afirmar un estado invariable y absoluto de la realidad física, la naturaleza cambia en sus elementos y compuestos, en función de las nuevas condiciones y equilibrios que se establecen entre las fuerzas físicas de la naturaleza. El mundo que nos es conocido, tanto en su expresión natural como cultural, es un mundo mutable y, por tanto, el conocimiento respecto a él también lo es. Los componentes "jurídicos" del derecho cambian del mismo modo, en razón de las distintas formas de relación instituidas por los hombres, y ello no lo hace menos real. Hoy, es una pretensión arcaica juzgar la cientificidad del derecho desde la perspectiva de la ciencia moderna cartesiana, es un craso error negarle el estatus de ciencia al derecho, tomando como 
modelo de ciencia a las matemáticas y a las ciencias naturales. Como señalamos anteriormente, el concepto de ciencia es situacional, y hoy no hay una definición universal respecto a ella, aunque aún le es esencial su afán de conocer la realidad de manera racional, ordenada y sistemática.

Desde esa perspectiva, queda la tarea de definir cuál es el objeto del derecho como ciencia. Afirmar que dicho objeto solo se circunscribe a la norma jurídica (como lo hace el positivismo jurídico) no es exacto, podemos, más bien, decir que el objeto del derecho como ciencia es lo "jurídico”, pero, ¿qué entendemos por ello?, o, más bien ¿qué componentes involucramos en dicho termino? Por lo pronto la norma, pero no solo en su contenido, sino también en cuanto a su eficacia, la conducta humana propia de cada contexto histórico, los valores que encauzan el deber ser que enuncian las proposiciones jurídicas, los paradigmas que sustentan los sistemas jurídicos, las causas que movilizan las normas al cambio y; otros más que sean considerados componentes de la realidad cultural que es el derecho. A esta visión de la ciencia jurídica y de su objeto de conocimiento, la denomino holística jurídica, puesto que pretende considerar la totalidad de los componentes de lo que llamamos "jurídico", reconociendo que no hay elementos totalmente exclusivos de una ciencia, puesto que la realidad vincula, de una u otra manera, sus componentes y la razón crea categorialmente limites que solo responden a la sistematización del conocimiento para una comprensión didáctica de la realidad. Así pues, se justifica la cientificidad del derecho desde una epistemología abierta a la posibilidad de conocer la realidad, que es una, pero que tiene, como lo afirmaba Parménides, manifestaciones diversas.

Finalmente, debo aludir a la investigación jurídica partiendo de la premisa que afirma que el método de investigación en cualquier ciencia debe determinarse por la naturaleza del objeto a considerar. En tal sentido, el «Derecho como ciencia» reclama un método propio diferente al de las ciencias naturales o formales. Quienes investigan en derecho deben ser creativos para generar nuevos enfoques metodológicos que ayuden a superar la parálisis cognitiva impuesta por el positivismo. El todo vale de Feyerabend, debe considerarse una visión oportuna para abrirle al derecho nuevas sendas hacia el conocimiento de la realidad jurídica y a la implementación de nuevas construcciones normativas, que respondan mejor a las 
anomalías que se plantean al paradigma jurídico imperante, cuando este ya no pueda satisfacer las expectativas de la sociedad organizada.

\section{CONCLUSIÓN}

Por consiguiente, de lo expuesto podemos concluir que: un análisis del desarrollo epistemológico en torno al conocimiento científico nos evidencia distintas etapas en el desarrollo de la ciencia moderna, pero, sobre todo, nos revela una realidad científica cambiante y evolutiva en el tiempo. La ciencia, fundamentalmente, no ha perdido su pretensión de conocer la realidad fenoménica de manera racional, sistemática y ordenada. Dicho objetivo, hoy se considera posible a través de diversos enfoques y herramientas metodológicas que superan el monismo metodológico impuesto por el positivismo inductivista del siglo decimonónico. Las discusiones en torno a la cientificidad del derecho se diluyen cada día más, y solo tienen eco en posiciones rígidas y anacrónicas. El derecho como ciencia es, también, un conjunto de conocimientos racionales, sistematizados y verificables, aunque de manera distinta a los conocimientos de otras ciencias. Una visión holística jurídica del objeto de la ciencia del derecho nos abre un espectro más amplio para la investigación jurídica, una diversidad de frentes, habida cuenta que el derecho como el resto de la realidad se muestra poliédrico en su manifestación fenoménica. Conocer esa diversidad de frentes del fenómeno jurídico hará que se posibilite conocimientos más cercanos a la realidad jurídica. Crear y establecer nuevos métodos y herramientas metodológicas en la investigación jurídica es un reto presente, para la imaginación de quienes hacen investigación en este campo. 


\section{BIBLIOGRAFÍA}

ATIENZA, Manuel (2001). El sentido del derecho, Barcelona, Ariel, p.242

CARNAP, R., (1978). "La superación de la metafísica mediante el análisis lógico del lenguaje" en A.J Ayer, El positivismo lógico, Fondo de cultura económica, Madrid, p. 85. Este artículo se publicó por primera vez en el volumen II de Erkenntnis en 1932.

FEYERABEND, Paul (1986). Tratado contra el método, esquema de una teoría anarquista del conocimiento. Editorial Tecnos, Madrid, España.

GARCÍA MAYNEZ, Juan (1960). La Definición del Derecho, Xalapa, México, p. 15.

KELSEN, Hans (1934). Reine Rechtslehre. Einleitung in die Rechtswissenschafiliche Problematik, Wien, F. Deuticke Verlag. Se emplea la edición castellana La Teoría pura del derecho. Introducción a la problemática científica del derecho, México, Editora Nacional, 1974, p. 17. Ahora, Reine Rechtslehre cit., p. 17.

KELSEN, Hans (1933). El método y los Conceptos fundamentales de la Teoría Pura del Derecho, versión dcl alemán por Luis Legaz Lacambra, Madrid, Edersa, p. 9.

MERCADO PÉREZ, David (2015). ¿Es el Derecho ciencia? Artículo derivado del Proyecto "El Lenguaje Como Constructor de la Realidad Jurídica" del grupo "Filosofía del Derecho y Derecho Constitucional" que se ejecuta en el Centro de Investigaciones de la Universidad Libre, Sede Cartagena, institución que avala al grupo en mención.

POPPER, Karl (1962). Lógica de la investigación científica, Tecnos, Madrid, la. Edición.

POPPER, Karl (1997). El mito del marco común. En defensa de la ciencia y la racionalidad, Paidós, Barcelona, p. 15.

POPPER, Karl (1991). La lógica de la investigación científica. México, Rei.

POPPER, Karl (1994). En busca de un mundo mejor, Paidós, Barcelona, p. 255.

POPPER, Karl (1985). Realismo y el objetivo de la ciencia, Tecnos, Madrid, p. 123.

STRAUSS, A. y J. CORBIN (1998). Fundamentos de la investigación cualitativa. Técnicas y procedimientos para desarrollar teoría puesta a tierra. Londres: Publicaciones SABIAS.

VÁSQUEZ ROCA, Adolfo (2006). La Epistemología de Feyerabend; Esquema de una teoría anarquista del conocimiento. Revista Observaciones filosóficas. En: http://observaciones.sitesled.com/ 

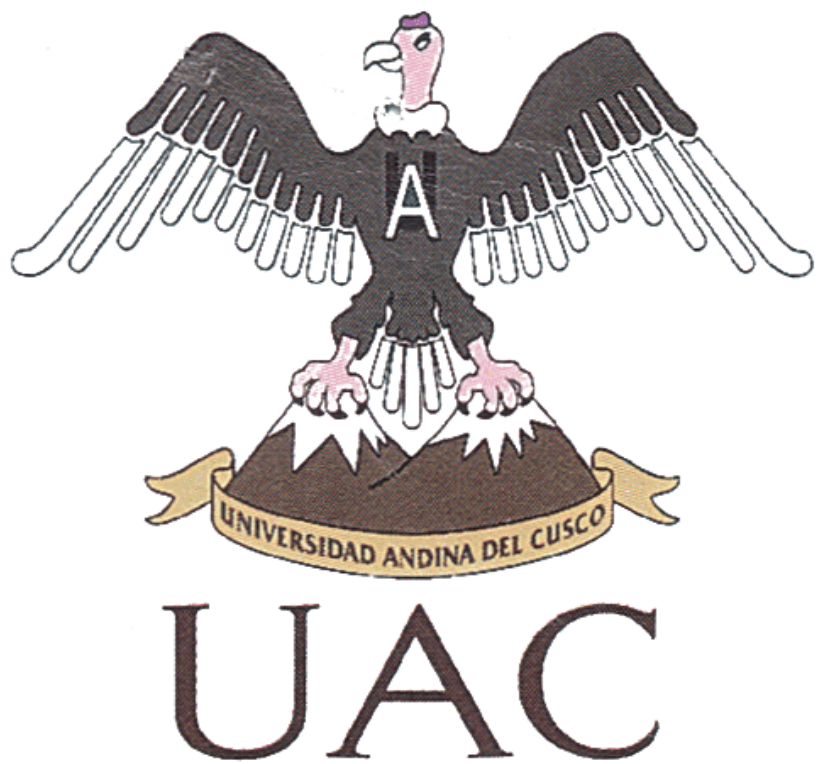

UNIVERSDAD ANDNM DEH CUSCO 